\title{
A Study of a Tissue Equivalent Gelatine Based
}

\section{Tissue Substitute}

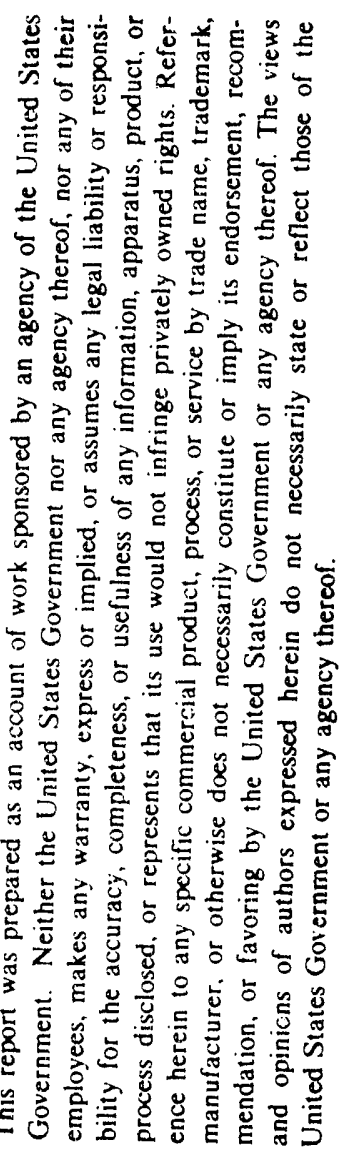

\author{
A Thesis \\ by \\ Jody L. Spence \\ Submitted to the Office of Graduate Studies of \\ Texas A\&M University \\ in partial fulfillment of the requirements for the degree of \\ MASTER OF SCIENCE \\ FGO5. 88 ER 60707
}

November 1992

Major Subject: Health Physics 


\begin{abstract}
A Study of a Tissue Equivalent Gelatine Based Tissue Substitute (November 1992)

Jody L. Spence, B.S., Texas A\&M University

Chair of Advisory Committee: Dr. Wesley E. Bolch
\end{abstract}

A study of several tissue substitutes for use as volumetric dosimeters was performed performed. The tissue substitutes studied included tissue substitutes from previous studies and from ICRU 44. The substitutes were evaluated for an overall match to Reference Man which was used as a basis for this study. The evaluation was based on the electron stopping power, the mass attenuation coefficient, the electron density, and the specific gravity. The tissue substitute chosen also had to be capable of changing from a liquid into a solid form to maintain an even distribution of thermoluminesent dosimetry (TLD) powder and then back to a liquid for recovery of the TLD powder with out adversely effecting the TLD powder.

The gelatine mixture provided the closest match to the data from Reference Man tissue. The gelatine mixture was put through a series of test to determine it's usefulness as a reliable tissue substitute. The TLD powder was cast in the gelatine mixture and recovered to determine if the TLD powder was adversely effected. The distribution of the TLD powder after being cast into the gelatin mixture was tested in insure an even was maintaıned.

The gelatine was easily changed from a liquid state to a solid state which could 
support an even distribution of the TLD powder. Recovery of the TLD was performed with relative ease and no adverse effects to the TLD powder. Therefore it was determined that the gelatine mixture was a suitable tissue equivalent substitute to be used for volumetric dosimetry studies. 
TABLE OF CONTENTS

ABSTRACT

TABLE OF CONTENTS

LIST OF FIGURES __ vi

LIST OF TABLES__ vii

CHAPTER

I INTRODUCTION

Present Study 2

II LITERATURE REVIEW

III MATERIALS AND METHODS_ 10

Gelatine 10

Reference Man $\quad 13$

Material Interaction Data $\quad 13$

Gelatine Preparation__ 16

Evaporation Study $\quad 18$

Sectioning Procedure_ $\quad 18$

TLD Powder Recovery 20

$\begin{array}{lll}\text { IV RESULTS } & 27\end{array}$

Assessment of Tissue Equivalency $\quad 27$

V CONCLLSIONS

REFERENCES $\quad 46$

APPENDIX A

APPENDIX B 51

APPENDIXC 


\section{CHAPTER I}

\section{INTRODUCTION}

A need for increased knowledge of the effects radiation produces in human body has increased the use of phantoms. A simple definition of a phantom is a mathematical or physical representation of a partial or whole object of interest. Phantoms which are representative of the human body and tissue are commonly used for dosimetry measurements and calculations. Mathematical phantoms are used for calculations in Monte carlo codes which are elaborate computer codes. These can be very accurate but are only calculations and are based on assumptions. Physical phantoms are needed to verify and improve the calculations obtained from Monte Carlo codes. The composition of a phantom can greatly effect the dosimetry measurements obtained. In 1906, an article was published in which Professor R. Kienbock, a Viennese radiologist, reasoned that 'an aluminum foil $1 \mathrm{~mm}$ thick is equivalent in absorption power to a layer of water or muscle, $1 \mathrm{~cm}$ thick' (Kienbock 1906). This was the beginning of the study of tissue substitutes.

Phantoms in this study will refer to a physical representation of a human or human tissue. Phantoms are constructed from a number of mixtures and compounds. The early phantoms consisted chiefly of water-filled volumes with simple geometries which provided fundamental characteristics of dose distribution in soft tissues. Wax was another of the first 
tissue substitutes used to produce phantoms for dosimetry measurements. These simple phantoms provided good basic data, but there are many diagnostic and radiotherapeutic applications which required a better match to the complex geometries and material composition of specific tissues (Hermann et al 1986 , stacey et al 1960). The need for improved phantoms with increased accuracy in the geometries produced and tissue matching has been stressed by many authors (Aissi and Poston 1984, white et al 1986, Golikov and Nikitin 1983, Hermann et al 1985).

Improvements in phantoms occurred as early as 1924 when Westman created a 'pelvic phantom' composed of wax and bolus alba, which was a mixture of two parts flour and one part china clay by weight, for gynecological measurements (stenstrom 1926). Since that time many improvements have been made in geometries and tissue substitutes. Some of the improved tissue substitutes consist of polyethylene-based, epoxy-resin based, and depolymerised natural rubber materials.

A further improvement in phantom materials was made with the decision to incorporate the detector in the tissue equivalent material. This approach has been taken by many experimenters and can be seen in the Rando phantom (White 1978, stacey et al 1961). The Rando phantom utilizes a human skeleton which is enclosed in thin sheets composed of synthetic isocyanate rubber with fillers of phenolic microspheres and antimony trioxide shaped to resemble a human torso. The phantom is sliced into thin sections which contain a series of small holes where thermoluminescent 
dosimeters (TLD) may be placed. The use of the Rando Phantom and TLD chips has become popular due to the dosimetry data that can be acquired from the phantom.

The dosimetry of the space remaining between the TLD chips, the small detectors, can not be measured and results in an assumption being made about the actual behavior of the radiation between the TLD chips. To improve on this model it was proposed that the detector, the TLD material, be distributed uniformly throughout the tissue of interest thus removing many of the uncertainties from other methods of measurements.

\section{PRESENT STUDY}

In this study, several tissue substitutes were examined for their possible use in the evaluation of isodose profiles. The selection was based on elemental composition, total mass attenuation coefficient, electron density, and electron stopping power of the potential substitutes. The tissue substitute was cast into various shapes and the retention of an even distribution of thermoluminescent dosimetry (TLD) powde: was studied.

The shapes that were cast will be sectioned into similarly sized smaller volumes to effectively evaluate the isodose profiles. This process could be suitable for any shape or geometry that can be cast from a liquid. The sectioning process should improve the TLD powder recovery since the smaller volumes will be easier to work with. 
Measurements will be made using TLD powder alone and TLD powder cast in the proposed tissue substitute by exposing the samples to a ${ }^{60} \mathrm{Co}$ gamma-ray source. One sample containing TLD powder will be sectioned and the dose per section measured. The total dose of the sectioned sample can be compared to the dose from the unsectioned specimen to verify a loss of less than approximately $3 \%$ of the TLD powder in the sectioning and recovery process.

To verify the process has no detrimental effects on the TLD powder two equal quantities of TLD powder will be exposed to a ${ }^{60}$ Co gamma-ray source and the resulting doses measured. prior to the exposure one sample will be put through the process of casting and recovery while the control TID powder will not. A comparison of the measured doses will indicate the effects the process had on the TLD powder. 
CHAPTER II

\section{Literature Review}

Research to develop a physical phantom for use in internal dosimetry experiments was begun in the 1970's by Poston and colleagues at the Oak Ridge National Laboratory (ORNL). During the research many types of detectors and tissue substitutes were used. Early investigations by Garry et al. (1975) used a physical construct of a mathematical phantom described by Fisher and snyder. The tissue substitute used by Garry et al. (1975) had a mass density of $1.0 \mathrm{~g} / \mathrm{cm}^{3}$. The tissue substitute was based on an evaluation of the mass attenuation coefficients of the different chemicals which were used. The material was liquid in form and therefore could not easily be handled. The phantom construct was filled with the tissue equivalent liquid into which a detector and source could be inserted. A Geiger-Muller counter, called a Phil, suitable for use in liquid was used for dose measurements. The detector was inserted into the liquid tissue substitute and moved to specific locations to obtain dose measurements. Experimental results, obtained at points in the phantom, were used to assign absorbed fractions of energy to selected organs of the body. These estimates were compared to results obtained from Monte Carlo calculations using the FisherSnyder phantom. The average percent difference bet:een the calculated and experimentally determined absorbed fractions was approximately $20 \%$. 
Mei et al. (1975) performed measurements using liquid tissue substitutes and methods similar to Garry et al. (1975). The investigators were interested in the effect of source organ size on absorbed fraction distribution. Source organs studied were the bladder and the stomach. Five different sizes of each organ were prepared for use in these experiments. An improvement in the previous methods of Gary et al. was the use of a better positioning device for the "Phil" detector. The measured absorbed fractions obtained by Mei et al. tended to vary less than the calculated absorbed fractions.

An improved phantom, Mr. Adam, and a new detector system were used by Stansbury and poston to measure the absorbed dose due to medical diagnostic x rays (Stansbury and Poston 1976). Two small, spherical NaI(TI) scintillation detectors were used in the measurements. The detectors were used to measure the spectrum of the $x$-rays inside the phantom at various points and the absorbed dose was calculated based on these data. The spectrum was a representation of the dose that was deposited internally. This method differed from the others by using a detector to measure the $x$-ray spectrum which was directly proportional to the dose deposited and not directly measuring the dose deposition.

Another approach was taken by chen and Poston (1976) by eliminating the use of relatively large detectors and using thermoluminescent dosimeters (TLD). The tissue substitute was the same as that used by Garry et al. (1975). The measurements 
were limited by the number of TLD chips used and the method of positioning the TLD chips. Primary focus was on the dose to the red bone marrow in children, ages one-year-old and five-yearsold, from diagnostic x-rays.

The research to this point had measured the dose at points with small detectors ard used the measurements to calculate the average organ dose (Aissi et al. 1982). The next step was to develop a volumetric dosimeter which would supply average absorbed doses for the entire organ. The development of a volumetric dosimeter was accomplished by Aissi et al. (1982). The dosimeter consisted of organic compounds and lithium fluoride (LiF) TLD powder. Previous studies had been performed with TLD chips but had encountered problems with positioning devices. With a TLD powder, the dosimeter could be spread uniformly throughout the organ of interest.

The tissue substitute used by Aissi and Poston (1987) consisted of paraffin and LiF TLD-100. To be effective, the tissue substitute needed to be solid during measurements to maintain the distribution of the LiF TLD-100 powder and to facilitate handling. At room temperature the paraffin did not remain solid; it would liquify. Therefore, tetrachlorobenzene was added to the paraffin mixture to solidify it at room temperature. The mixture had a specific gravity which was less than the snyder tissue due to the substitution of carbon for oxygen in the mixture. The mass attenuation coefficients of carbon and oxygen were almost identical from approximately $20 \mathrm{keV}$ 
to $4 \mathrm{MeV}$. Virtually all radiations considered for internal dosimetry are within this energy range. Therefore, th s mixture of material was considered a suitable tissue substitute and was named the pate dosimetry system because the main constituents were paraffin and tetrachlorobenzene.

The Pate dosimetry material was prepared by mixing specific amounts of paraffin and tetrachlorobenzene. Then $0.5 \%$ LiF TLD100 powder was added to the mixture as it cooled. After exposure, the Pate material could be dissolved by rinsing the paraffin mixture with a combination of heated water and an organic solvent. The TLD-100 powder was retrieved by filtering the liquid mixture through a wire mesh sieve.

The Pate dosimetry system provided volume-averaged absorbed dose estimates to the tissues in the phantom. To determine isodose profiles the organ had to be sectioned into uniformly sized volumes. This was a problem in the use of the pate system. The organs could be sliced by an electrinally heated wire but the cut "healed" rapidly as the pate mixture cooled to solidification temperature. To solve this problem an electrically heated knife with a thin metal blade was tried. Once again the pate mixture healed rapidly and no uniform sections could be obtained.

There have been many attempts to improve tissue equivalent materials and much research has been performed in the area of tissue equivalence. Most of the research has been performed with liquid materials, rubber based materials, or hard plastics. One area that seems to be neglected is in the area of gelatine based 
tissue equivalents. Early work with gels was performed by Rossi and Failla (1956) and Frigerio (1962). The primary emphasis on their research was the fabrication of tissue-equivalent ionization chambers. The development of tissue equivalent plastics suitable for such use led to a lack of interest in gelbased tissue-equivalent materials. Subsequent literature references to gelatine based tissue equivalent materials were not found. 
CHAPTER III

\section{MATERIALS AND METHODS}

\section{GELATINE}

Over 50 percent of the human body is composed of cllagen, the protein of tendon and skin. Collagen is a triple helical chain of amino acids with inter-chain hydrogen bonding. Three left handed chains twist about each other to form a three stranded right-handed superhelix. The three strands are held together by hydrogen bonds between the glycine residues and between the $-\mathrm{OH}$ groups of hydroproline (Morrison and Boyd 1983, Hall 1961).

Gelatine is tormed when collagen is boiled in water and allowed to cool. The boiling water denatures the collagen by breaking the hydrogen bonds and causing an irreversible precipitation of proteins. The broken hydrogen bonds of the collagen are reformed with the water molecules. The newly formed hydrogen bonds create new chains but not in a helical structure and result in the gelatine having a molecular weight one third that of the original collagen (Morrison and Boyd 1983). The water molecules are attached to the proteins as shown in Fjgure 1 (Veis 1964).

The gelatine used in this study is commercially available and is produced by kind and knox from porkskin. A listing of the amino acids and the percentage of each in the gelatine is given in Tabie 1 (Kind and Knox 1992). 
Figure 1. Water binding to gelatin by weak hydrogen bonds. 
Table 1. Basic composition of Gelatine

\begin{tabular}{|c|c|}
\hline Amino Acid & Mass Percentage \\
\hline Alanine & 8.6 \\
\hline Arginine & 8.3 \\
\hline Aspartic Acid & 6.2 \\
\hline Glutamic Acid & 1.1 .3 \\
\hline Glycine & 26.4 \\
\hline Hydroxylysine & 1.04 \\
\hline Hydroxyproline & 13.5 \\
\hline Isoleucine & 1.36 \\
\hline Leucine & 3.1 \\
\hline Lysine & 4.1 \\
\hline Phenylalanine & 2.1 \\
\hline Proline & 6.2 \\
\hline Serine & 2.9 \\
\hline Threonine & 2.2 \\
\hline Valine & 2.5 \\
\hline
\end{tabular}




\section{REFERENCE MAN}

To effectively model the human body it was necessary to select a substance that would mimic human tissue as closely and thoroughly as possible. Before comparisons could be performed and a tissue equivalent material selected it was necessary to define the parameters to be duplicated. Reference Man, as defined in ICRP 23, was chosen to be the standard due to the extensive amount of data available and the wide use of the data in Monte Carlo codes. The elemental composition for Reference Man that was selected for this study was for elements that were in excess of 2 percent by mass and are shown in Table 2.

\section{INTERACTION DATA}

Electron stopping power data for individual elements and several compounds are given in ICRU 37. The electron stopping power of the tissue substitutes was calculated usi.ng the equation

$$
\left(\frac{d T}{\rho d x}\right)_{m<x}=f_{z 1}\left(\frac{d T}{\rho d x}\right)_{: 1}+f_{z 2}\left(\frac{d T}{f d x}\right)_{z 2}+\ldots \quad E q 1
$$

where $\left(\frac{d T}{\rho d x}\right)_{m i x}$ is the total electron stopping power, $f_{z l}$ is the weight fraction of element $z 1$, and $\left(\frac{d T}{\rho d x}\right)_{: 1}$ is the elemental electron stopping power (Attix 1.986).

The total mass attenuation coefficient was calculated using equation 2. The elemental composition by weight of Reference Man 
Table 2. Elemental Composition of Reference Man

\begin{tabular}{|c|c|}
\hline Element & Percent by Weight \\
\hline $\mathrm{H}$ & 10.4 \\
\hline $\mathrm{C}$ & 23.8 \\
\hline $\mathrm{O}$ & 63.1 \\
\hline $\mathrm{N}$ & 2.7 \\
\hline
\end{tabular}


was used to calculate the total mass attenuation coefficient. Since the attenuation coefficient is dependent upon the energy and the radiation, the attenuation coefficient was calculated at various energies from $10 \mathrm{keV}$ to $4 \mathrm{MeV}$.

The candidates to be considered for use as a tissue equivalent substitute were taken from prior studies and from ICRU 44. The substitutes were chosen from a list provided in ICRU 44 based on their ability to be cast into shapes and then reliquified for TLD powder recovery.

For the substitutes chosen, the elemental and atomic composition were listed for use in calculations for tissue substitute comparisons. The electron stopping power, the mass attenuation coefficient, and the electron density were calculated for the tissue substitutes using the same methods as those for Reference Man.

The code used to calculate the electron stopping power used data taken from ICRU 37 (1984). The data were both element and energy dependent. Therefore a simple program was written to retrieve the data from memory and use the data in equation 5 with the elemental data of the tissue substitute. A listing of this program is given in appendix $A$.

The code used for calculating the mass attenuation coefficient was similar to that used for electron density calculations. The attenuation data vas taken from the Health Physics and Radiological Health Handbook (Shleien and Terpilak 1987). The data is used with equation 2 and the elemental data 
of the tissue substitute. A listing of this program is given in appendix $B$.

\section{GELATINE PREPARATION}

The gelatine was mixed in a ratio of 10 percent powdered gelatine and 90 percent distilled water. The mixture of ten percent gelatine was chosen based on the carbon content of the gelatine and Reference Man. The distilled water was divided into two parts of 40 and 60 percent. The smaller portion was mixed with the gelatine in a beaker and allowed to set for a period of five minutes.

The larger portion of the water was heated to boiling. The boiling water was added to the cold gelatine mixture and agitated until all the gelatine mixture was dissolved. The gelatine mixture was allowed to cool for approximately 3 to 4 minutes to a temperature of $65^{\circ} \mathrm{C}$. The cooling process allowed the mixture to reach a temperature that would not burn or adversely effect the mold or molding process. The cooled gelatine could then be poured into the mold of interest.

Before the Einal mixing of the gelatine the mold the gelatine was to be cast into was prepared. The mold used in this study was a bowl that would yield a thin circular disk of the tissue substitute. The mold was lined with a thin sheet of clear polyethylene. The lining was added to assist in the removal of the hardened, shaped substitute from the mold. The polyethylene lining used was less than 0:.1 millimeter in thickness. The 
Iining prevented some of the gelatine mixture from a possible loss while removing the solidified tissue substitute from the mold. The lining was not rigid and therefore could be easily peeled from the gelatine mixture.

A mixture of 1 percent TLD powder by mass was used in the volumetric dosimeter. Prior to pouring the gelatine into the mold to be mixed with the TLD powder, the container volume was measured by filling the mold with water, without the lining. The amount of water was then measured by transferring it the a graduated cylinder. The mold was carefully examined for any traces of water that might not have been transferred to the graduated cylinder. If any drops of water were noticed, a teflon spatula was carefully employed to remove the water and place it in the graduated cylinder. Once the amount of gelatine that was required to fill the mold was obtained, the needed quantity of TLD powder was calculated. The required quantity of TLD powder needed was then measured using a balance.

After the gelatine mixture was poured into the mold, it was allowed to cool for five minutes. During this time the gelatine thickened slightly, decreasing the setting rate. The TLD powder was added to the mixture and stirred for two minutes. There was a slight loss of TLD powder and gelatine which came into contact with the cool surface of the mixing stick. The gelatine mixture containing the TLD powder as then nlaced into a refrigerator to speed the setting of the mixture, thus reducing the settling time and ensuring a more uniform distribution of powder. 
After complete setting, the gelatine mixture containing the TLD powder was removed from the mold. The polyethylene lining was carefully peeled from the formed tissue substitute to keep from tearing and losing parts of the formed shape. The formed substitute was ready to be used for exposure to radiation.

\section{EVAPORATION STUDY}

The gelatine mixture was tested for the rate of water loss due to evaporation. A sample of the gelatine mixture was weighed immediately after it had set and become firm. The sample was weighed at fifteen minute intervals using a balance. After two hours the intervals were extended to one hour. Measurements were taken for a period of 48 hours.

\section{SECTIONING PROCEDURE}

To test the uniformity of the distribution of the TLD powder, a cylindrically shaped substitute was prepared. The mold used for the shape was a $100 \mathrm{~mL}$ beaker. The formed substitute was sectioned both vertically and horizontally as shown in Figure 2. The sections were weighed and then the TLD powder was recovered. The mass of the recovered TID powder was measured using a balance. The weight of the TLD powder was divided by the total weight of the section to yield the percentage of TLD powder in the section. Gomparison of these results for all sections provided the actual distribution of the TLD powder both vertically and horizontally. 

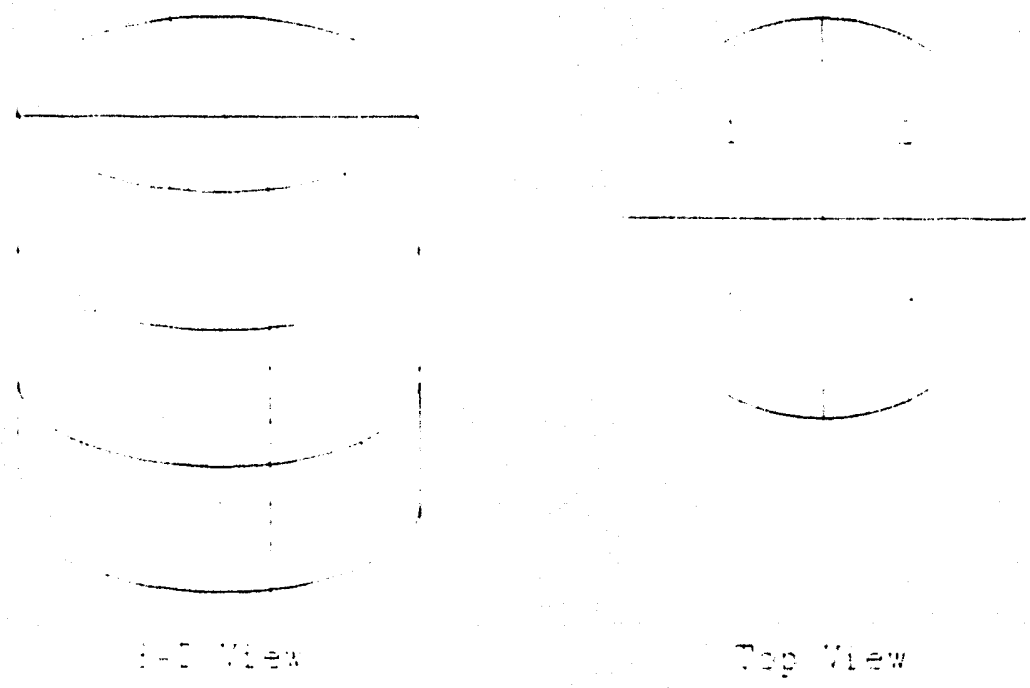

Figure 2. Section of Cylinder for TLD Powder Distribution verification. 


\section{TLD POWDER RECOVERY}

To recover the TLD powder from the gelatine mixture the solid substitute must be returned to a liquid state. This was accomplished by dissolving the solid substitute in hot water. The water was heated to a temperature of $65^{\circ} \mathrm{C}$ and mixed with the solid substitute. The solid substitute dissolved in the heated water. The heated water was hot enough to easily melt the solidified gelatine mixture while remaining well below the temperature required of the TLD powder of approximately $100^{\circ} \mathrm{C}$ to clear any stored information.

The liquified mixture was then poured through a filter system as shown in Figure 3. The filter system consisted of a filter holder, a filter, a rubber stopper, an Erlenmeyer flask, and an aspirator. The filter holder secured the filter between two rubber gaskets while being capable of holding $100 \mathrm{~mL}$ of liquid. A 200 mesh TLD powder was used in the gelatine mixture. The gelatine mixture was filtered with a 400 mesh screen to ensure no direct loss of the TLD powder in the filtering process. As water passes through the aspirator, air is drawn from the Erlenmeyer flask creating a vacuum. The rubber stopper creates an air tight seal between the Erlenmeyer flask and the filter holder. Therefore, the liquified gelatine mixture and the heated water rinse are drawn through the filter leaving the TLD powder.

The TLD powder had a tendency to settle to the bottom of the liquified mixture and deposit itself on the bottom of the beaker. Therefore, a rinse bottle was filled with heated water and used 

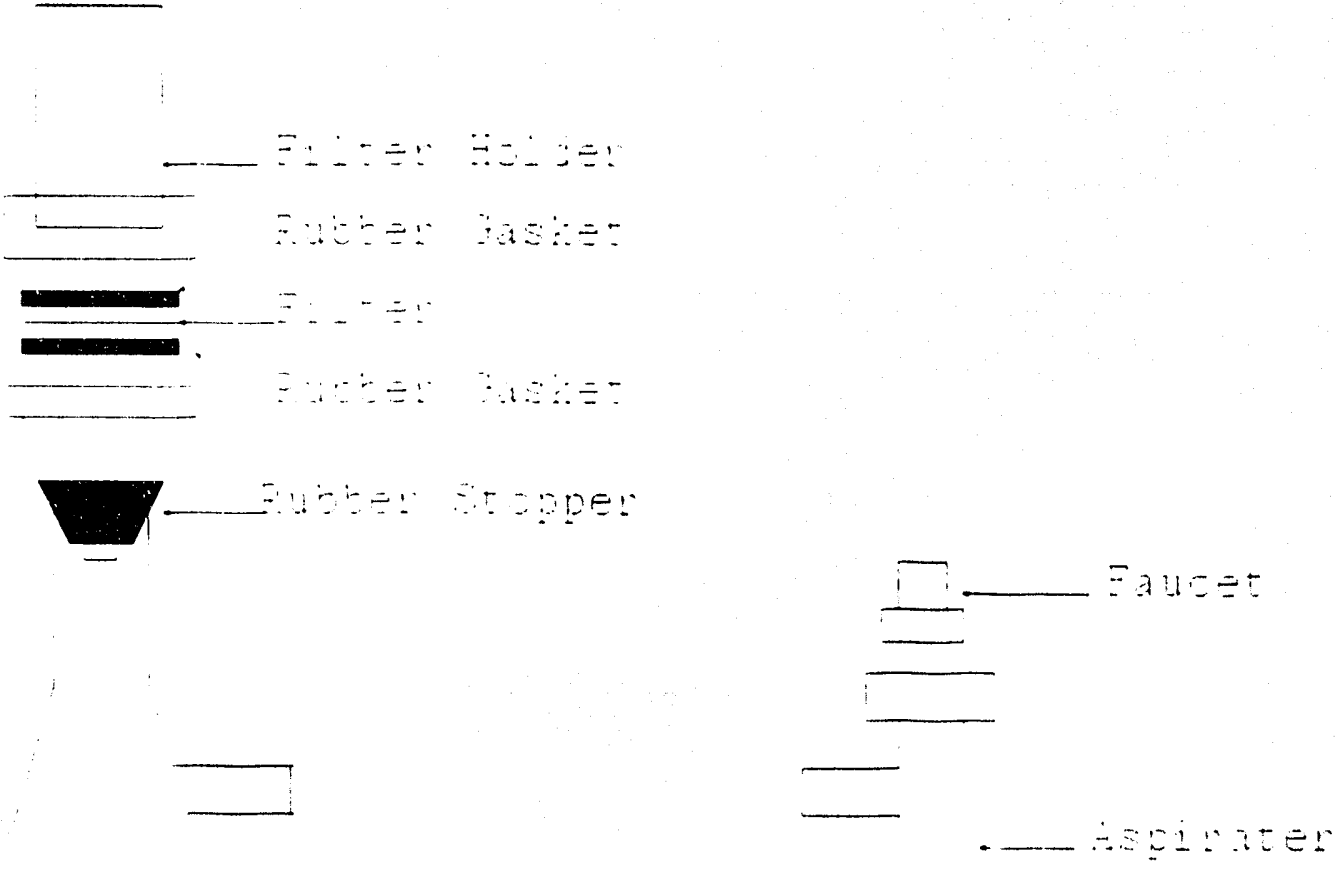

-

Figure 3. TLD Powder Recovery system. 
to rinse the beaker clean of TLD powder. The TLD powder also tended the deposit on the sides of the filter holder and the upper filter gasket. The rinse bottle was employed to remove the TLD powder from the sides of the holder and the gasket depositing all of the TLD powder on the filter. Additional water was sprayed through the TLD powder and filter to insure complete removal of any gelatine residue.

After deposition of the TLD powder on the filter, the aspirator was disconnected and the filter removed from the system. The TLD powder remained moist and was set aside and allowed to air dry. After drying, the filter was placed above a weighing paper and the powder carefully removed with a stiff, short haired brush. Care was taken not to lose any powder due to excessive force while brushing. Also, after removal of the powder from the filter, the brush was checked for powder residue to ensure as little loss as possible. The recovered TLD powder was then weighed and recorded. After all sections were recovered and weighed the amounts of TLD powder recovered were summed to estimate the total loss of TLD powder.

The ensure the process of mixing the TLD powder with a heated, water based gelatine mixture did not interfere with the properties of the TLD powder, two TLD powder samples, one which was put through the solidification and recovery process and a control, nere irradiated and examined.

Both samples were exposed to a $35 \mathrm{mci}{ }^{60} \mathrm{Co}$ gamma-ray source for approximately 60 minutes. The samples were placed on a table 
twelve inches from the radioactive source as shown in Figure 4 . The source was held in place directly above the samples by a specially designed apparatus. No account was made for backscattering since it was assumed both samples would receive the same amount of radiation via primary or secondary interactions.

The exposed samples were then read using a Harshaw Model 2000A Reader and a Harshaw Model 2080 TL Picoprocessor following the procedure outlined by Henson (1987). The control TLD powder was read in the TLD reader first to eliminate the occurrence of any possible problems resulting from any remaining gelatine in the sample TLD powder. To use powder in the reader, a special dispenser which distributes the same amount of powder for each reading was used. The dispenser is shown in Figure 5. The powder was placed in the holding cup of the dispenser which, when aligned with the hole in the sliding measuring drawer, deposits enough powder to fill the cavity. The holding cup was then moved from over the hole in the drawer and the drawer was aligned with the release hole of the powder distributer. The mechanism must be over the TLD reader tray prior to depositing the powder on the tray to ensure proper positioning of the powder for heating. The reader was set to heat to a maximum temperature of $250^{\circ} \mathrm{C}$ and hold at that temperature during the reading. The powder was read from the time of initial heating to the maximum temperature of $250^{\circ} \mathrm{C}$ for a total time of 80 seconds. This was repeated for all the individual portions of TLD powder. 


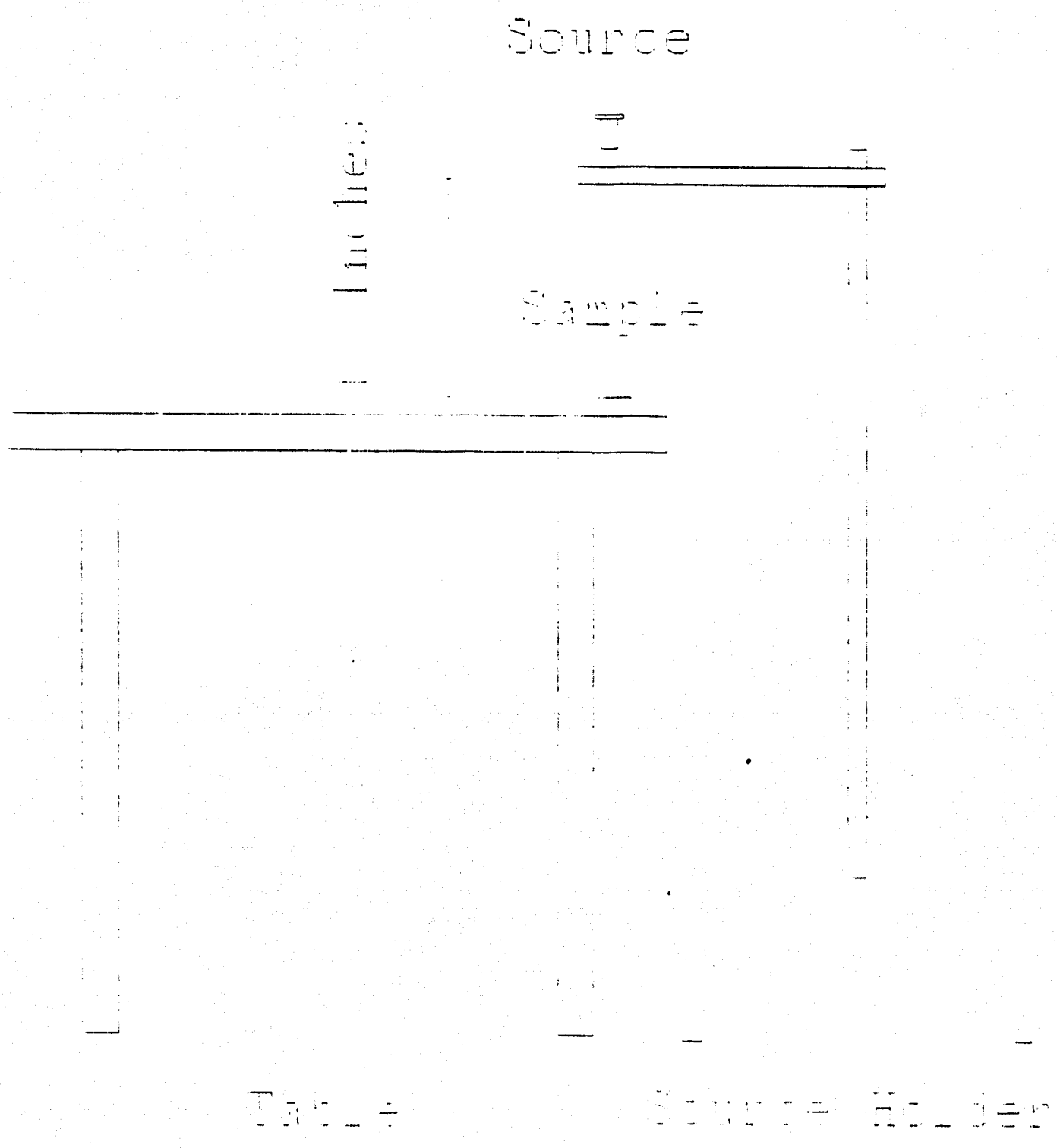

Figure 4. Sample Irradiation Geometry. 
$\because 2$

Fowier tolje:

Mountlag Hige
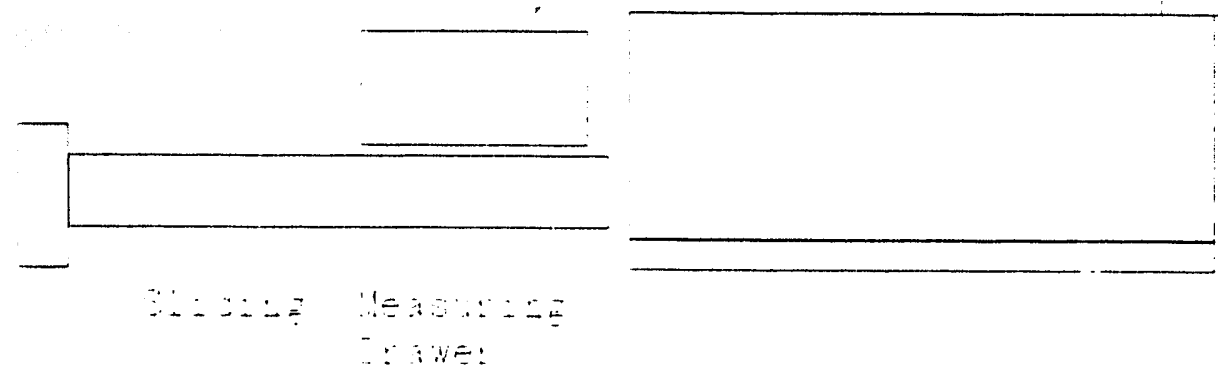

$\because \because y$

Figure 5. Harshaw Reader TLD Powder Distributor 
The data from the reader were assembled into usable data and displayed on the picoprocessor. Of the five peaks that are characteristic for LiF, a region of interest was selected containing the second through fifth peaks. The first peak was omitted due to its short half-life. The data were recorded and entered into a Computerized Glow Curve Deconvolution (CGCD) program from Harshaw. The program was used to determine the area under the glow curve in units of uC. This program was used for all measurements in this study. 
CHAPTER V

RESULTS

\section{ASSESSMENT OR TISSUE EQUIVALENCY}

To effectively match a tissue substitute to that of Reference Man, the closest calculated overall match between the substitutes studied was chosen. The data used to determine the best suited substitute are presented in both tabular and graphic form.

Several tissue substitute candidates were chosen for comparison in this study from previous research and from ICRU 44. Many substitutes were not used in this study due to the physical state of the substitute. To be of use as a volumetric dosimeter, the substitute had to be easily sectioned and dissolved without adversely effecting the TLD powder. The substitutes that were chosen for comparison in this study were the Pate system, a gelatine system, and A-150 tissue equivalent plastic.

The elemental data for Reference Man and the three substitutes are presented in Table 3 by mass percentage. In Table 3 it is noted that the Pate system has no oxygen or nitrogen. A-150 plastic has a much lower percentage of oxygen than Reference Man essentially substituting carbon for oxygen, but the hydrogen content is very similar. The closest match of the three is gelatine. The oxygen content is slightly higher and the carbon content slightly lower than that in Reference Man, but of the substitutes presented it is the most representative of 
Table 3. Elemental composition of tissue substitutes presented by weight percentages.

\begin{tabular}{|c|c|c|c|c|}
\hline \hline Element & Ref. Man & Gelatine & Pate & A-150 \\
\hline $\mathrm{H}$ & 10.4 & 9.2 & 15 & 10.5 \\
\hline $\mathrm{C}$ & 23.8 & 18.3 & 85 & 80.5 \\
\hline $\mathrm{O}$ & 63.1 & 67.2 & 0 & 5.4 \\
\hline $\mathrm{N}$ & 2.7 & 5.3 & 0 & 3.6 \\
\hline
\end{tabular}


Reference Man based on elemental composition.

The rate of evaporation was found to be very small and it decreased with time. Therefore it was determined that evaporation was not a controlling factor in the use of a gelatine base tissue equivalent substitute.

Most of the photon interactions will occur with electrons. The electron density data for the substitutes are listed in Table 4. The electron density is approximately the same for oxygen, carbon, and nitrogen, hydrogen is roughly twice that of the others. The Bragg rule applies to electron densities (Attix 1986) and therefore the electron densitiəs of mixtures are weighted ratios of the elemental electron densities. A-150 plastic has the same electron density as Reference Man tissue. Gelatine has a difference of $1 \%$ while the Pate system has a difference of $4 \%$.

The electron stopping powers were calculated using the method previously discussed. The results are shown in Figure 6 and the data is given in Table 5. From the data it can be seen that at energies greater than $30 \mathrm{keV}$ the electron stopping power for the substitutes are approximately equal. For low energies, energies below $30 \mathrm{keV}$, it is noted that the pate system has a higher electron stopping power than while the gelatine mixture and A-150 plastic have a lower electron stopping power.

The data in Table 5 shows the percent difference bet:leen the tissue substitutes and Reference Man. As in Figure 6, the Pate system has a higher electron stopping power, in contrast the 
Table 4. The calculated electron densities of the tissue substitutes.

\begin{tabular}{|c|c|}
\hline Tissue Substitute & Electron density $(\mathrm{e} / \mathrm{g})$ \\
\hline & $3.32 \star 10^{\wedge 23}$ \\
\hline Gelatine & $3.28 * 10^{\wedge 23}$ \\
\hline Pate & $3.45 \star 10^{\wedge 23}$ \\
\hline $\mathrm{A}-150$ & $3.32 \star 10^{\wedge 23}$ \\
\hline
\end{tabular}


$50-$

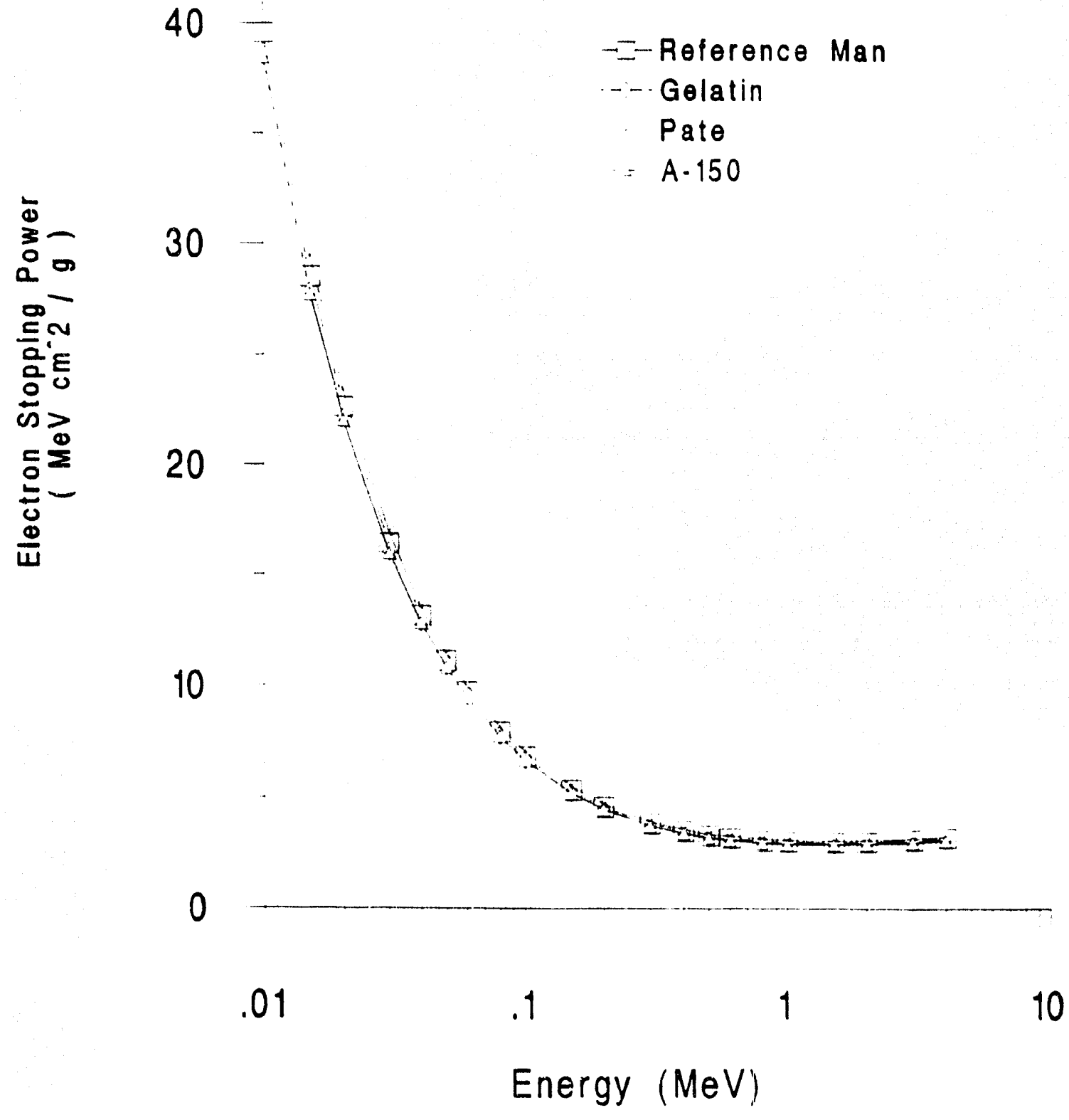

Figure 6. Comparison of the Calculated Electron stopping Powers of Tissue Substitutes as Energy Levels Increase. 
Table 5. Electron Stopping Power Data. The data for the tissue substitutes is given as a percent difference from Reference Man.

\begin{tabular}{|c|c|c|c|c|}
\hline $\begin{array}{c}\text { Energy } \\
(\mathrm{MeV})\end{array}$ & $\begin{array}{l}\text { Reference Man } \\
(\mathrm{MeV} \mathrm{cm} 22 / \mathrm{g})\end{array}$ & Gelatine & Pate & $A-150$ \\
\hline 0.01 & 39.56 & 2.45 & -3.34 & 2.76 \\
\hline 0.015 & 28.52 & 2.42 & -3.26 & 2.73 \\
\hline 0.02 & 22.64 & 2.39 & -3.22 & 2.69 \\
\hline 0.03 & 16.43 & 2.37 & -3.10 & 2.73 \\
\hline 0.04 & 13.15 & 2.28 & -3.12 & 2.66 \\
\hline 0.05 & 11.11 & 2.25 & -3.15 & 2.61 \\
\hline 0.06 & 9.73 & 2.36 & -2.98 & 2.67 \\
\hline 0.08 & 7.94 & 2.27 & -3.02 & 2.64 \\
\hline 0.1 & 6.85 & 2.34 & -2.92 & 2.77 \\
\hline 0.15 & 5.35 & 2.24 & -2.99 & 2.61 \\
\hline 0.2 & 4.60 & 2.17 & -2.83 & 2.82 \\
\hline 0.3 & 3.86 & 2.33 & -2.59 & 2.84 \\
\hline 0.4 & 3.51 & 2.27 & -2.56 & 3.13 \\
\hline 0.5 & 3.31 & 2.11 & -2.42 & 3.02 \\
\hline 0.6 & 3.19 & 2.19 & -2.82 & 2.82 \\
\hline 0.8 & 3.07 & 2.28 & -2.28 & 2.93 \\
\hline 1.0 & 3.02 & 2.31 & -2.32 & 3.31 \\
\hline 1.5 & 3.01 & 2.32 & -1.99 & 3.65 \\
\hline 2.0 & 3.04 & 1.97 & -1.97 & 3.62 \\
\hline 3.0 & 3.12 & 1.92 & -1.92 & 3.53 \\
\hline 4.0 & 3.21 & 1.86 & -1.87 & 3.74 \\
\hline
\end{tabular}


gelatine mixture and A-150 plastic have a slightly lower electron stopping power. At low energies the gelatine mixture is the best match for Reference Man. The A-150 plastic is only a little less of a match at low energies but at higher energies it starts to become worse while the gelatine data only provides a continually improving match to Reference Man. The Pate system provided the worst data of the substitutes studied at energies below $30 \mathrm{keV}$. At energies above $30 \mathrm{keV}$ the Pate system proved to be a better match than the A-150 plastic and approximately an equal match to the gelatine mixture.

The mass attenuation coefficient dara was calculated using methous described earlier. The results are shown in Figure 7 and the data is given in Table 6. From the graph it can be seen that at energies greater than $40 \mathrm{keV}$ the mass attenuation coefficients for the substitutes are approximately equal. For energies below $40 \mathrm{keV}$, mass attenuation coefficients for the pate system and the A-150 plastic are much smaller than those of Reference Man. The gelatine mixture data provide a much closer match to the values for Reference Man tissue. From Table 6 the percent differences for the Pate system and the A-150 plastic at low energies range from $9 \%$ to $48 \%$ and $9 \%$ to $37 \%$, respectively. The data for the gelatine mixture ranges from $0 \%$ to $10 \%$ and proves to be a much better match to the data for Reference Man tissue. At energies above 40 tey 711 tissue substitutes matched Reference Man tissue.

The selection of the tissue substitute was based on all the 
$3-$

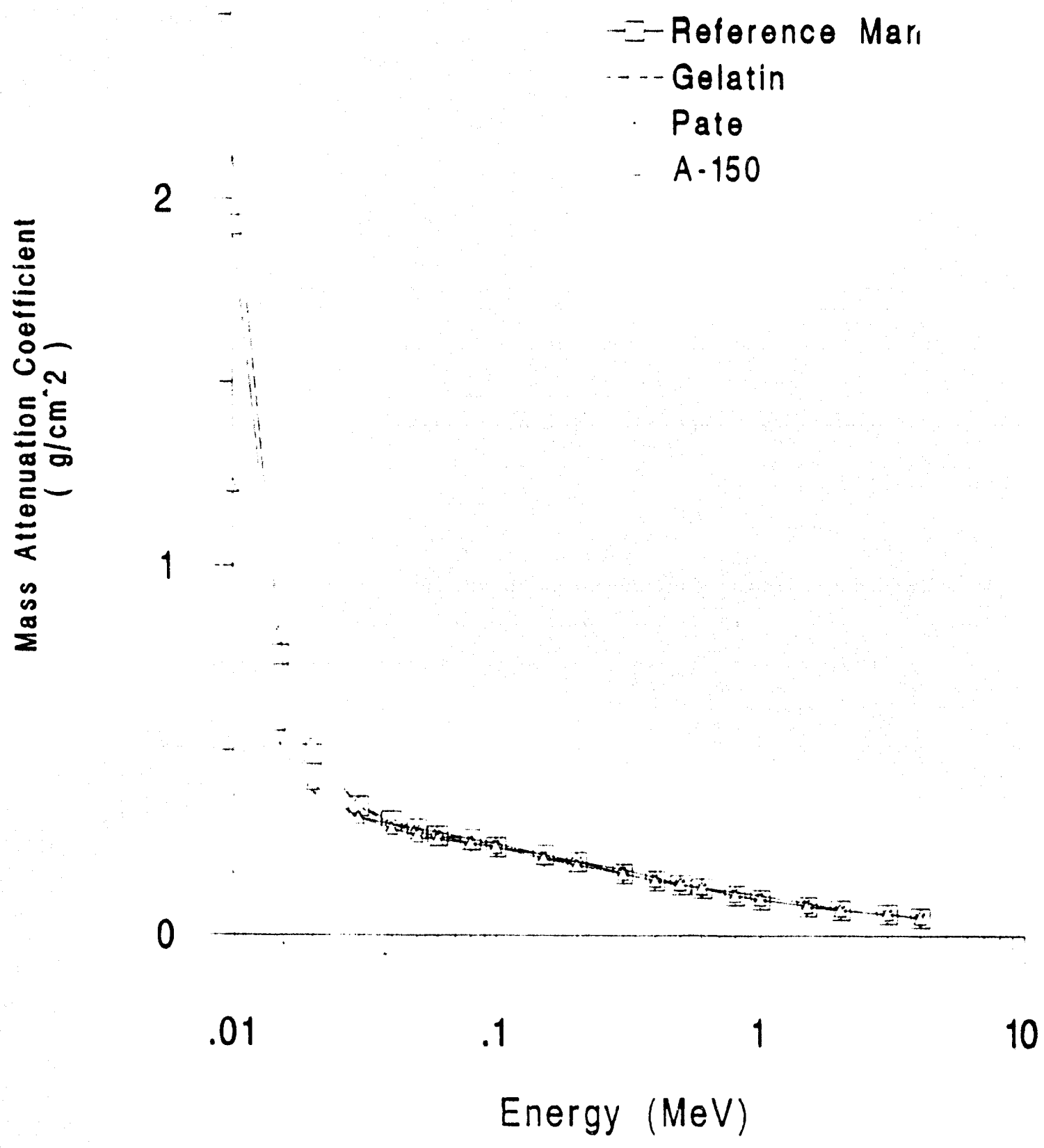

Figure 7. Mass Attenuation Coefficient 
Table 6. Mass Attenuation Coefficient Data. The data for the tissue substitutes are given as a percent difference from the data of Reference Man tissue.

\begin{tabular}{|c|c|c|c|c|}
\hline $\begin{array}{c}\text { Energy } \\
(\mathrm{MeV})\end{array}$ & $\begin{array}{c}\text { Reference Man } \\
\left(\mathrm{g} / \mathrm{cm}^{\wedge} 2\right)\end{array}$ & Gelatine & Pate & $A-150$ \\
\hline 0.01 & 1.93 & -10.89 & 48.19 & 36.79 \\
\hline 0.015 & 0.76 & -6.58 & 31.58 & 25.00 \\
\hline 0.02 & 0.49 & -4.08 & 20.14 & 16.33 \\
\hline 0.03 & 0.35 & 0.00 & 8.57 & 8.57 \\
\hline 0.04 & 0.31 & 3.22 & 3.22 & 6.45 \\
\hline 0.05 & 0.29 & 3.45 & 0.00 & 6.90 \\
\hline 0.06 & 0.27 & 0.00 & -3.70 & 3.70 \\
\hline 0.08 & 0.26 & 3.84 & 0.00 & 3.84 \\
\hline 0.1 & 0.24 & 0.00 & -4.17 & 0.00 \\
\hline 0.15 & 0.22 & 4.54 & 0.00 & 4.54 \\
\hline 0.2 & 0.20 & 0.00 & 0.00 & 5.00 \\
\hline 0.3 & 0.17 & 0.00 & -5.88 & 0.00 \\
\hline 0.4 & 0.15 & 0.00 & -6.67 & 0.00 \\
\hline 0.5 & 0.14 & 0.00 & 0.00 & 0.00 \\
\hline 0.6 & 0.13 & 0.00 & 0.00 & 0.00 \\
\hline 0.8 & 0.11 & 0.00 & -9.10 & 0.00 \\
\hline 1.0 & 0.10 & 0.00 & -10.00 & 0.00 \\
\hline 1.5 & 0.08 & 0.00 & -12.5 & 0.00 \\
\hline 2.0 & 0.07 & 0.00 & 0.00 & 0.00 \\
\hline 3.0 & 0.06 & 0.00 & 0.00 & 0.00 \\
\hline 4.0 & 0.05 & 0.00 & 0.00 & 0.00 \\
\hline
\end{tabular}


comparisons made to the data of Reference Man tissue. The elemental composition of the gelatine mixture gave the closest match to that of Reference Man tissue by having the largest amount of oxygen and an equal amount of hydrogen. The electron densities of all the observed substitutes were approximately equal with A-150 plastic have a slightly better match than the remaining substitutes.

The gelatine mixture gave the closest match of the studied substitutes at all energies to the electron stopping power data of Reference Man tissue. The mass attenuation coefficient for the substitutes was approximately the same for the substitutes for energies above $40 \mathrm{keV}$. At energies below $40 \mathrm{kev}$ the gelatine mixture agreed closest with the dat a Erom Reference Man tissue with the other substitutes having a uifference of 3 to 4 times that of gelatine. Based on these results the gelatine mixture was chosen as the tissue substitute to be used in the procedure for dose measurements.

With gelatine being the tissue substitute of choice, several tests were performed to identify the properties of the gelatine mixture. The first answer sought was the rate of evaporation. The rate of evaporation was calculated by methous discussed earlier in this study. The water evaporated at a very slow rate which decreased with time. Thus the evaporation rate will not be a controlling factor in the use of gelatine based phantoms.

The density of the $10 \%$ gelatine mixture was measured and found to be $1.09 \mathrm{~g} / \mathrm{cm}^{\wedge}$. From ICRP 23 (ICRP 1975) the density 
for the total body of Reference Man was stated as being 1.07 $\mathrm{g} / \mathrm{cm}^{\wedge} 3$. There is a $2 \%$ difference between the gelatine based mixture and Reference Man. This compares favorably and indicates the gelatine is a good choice as a tissue substitute.

To verify the sectioning procedure tro samples of the gelatine mixture were prepared for exposure. Two $100 \mathrm{~mL}$ samples of the gelatine mixture, containing $1 \%$ TLD powder, were prepared. The liquid gelatine mixture was poured into $100 \mathrm{ml}$ beakers which were used as molds. The solidified forms were removed from the molds and the lining was carefully remored. The samples were then exposed to a $35 \mathrm{mCi}{ }^{60} \mathrm{Co}$ source for approximately 60 minutes. The samples were placed a distance of 12 inches from the radioactive source as shown in Figure 4.

After exposure to the source, one sample was divided into 12 sections as shown in Figure 2. The TLD powder vas recovered from each section separately as described earlier. The TLD powder from the unsectioned forin was recovered and retained as a whole. The results from the test for uniformity of TLD powder distribution are shown in Table 7. There was a slight loss of approximately one gram of the gelatine mixture. The loss probably occurred during the separation of the gelatine from the polyethylene lining. The horizontal distribution of TLD powder was approximately uniform varying form $0.5 \%$ to $1 \%$. The greatest variance occurred in the upper most portions of the sample. The vertical distribution of TLD powder varied from top to bottom by 2.5\%. The variance in TLD powder distributions can be attributed 
Table 7. Distribution of TLD powder in the gelatine mixture.

\begin{tabular}{|c|c|c|c|}
\hline Section & $\begin{array}{c}\text { Total Weight } \\
\text { of Section (g) }\end{array}$ & $\begin{array}{c}\text { Weight of } \\
\text { TLD Powder (g) }\end{array}$ & $\begin{array}{c}\text { Percentage of } \\
\text { TLD Powder }\end{array}$ \\
\hline $1-1$ & 8.65 & 0.083 & 0.965 \\
\hline $1-2$ & 8.96 & 0.086 & 0.960 \\
\hline $1-3$ & 9.78 & 0.093 & 0.955 \\
\hline $1-4$ & 10.31 & 0.099 & 0.962 \\
\hline $2-1$ & 6.34 & 0.061 & 0.964 \\
\hline $2-2$ & 5.51 & 0.053 & 0.967 \\
\hline $2-3$ & 6.61 & 0.064 & 0.966 \\
\hline $2-4$ & 6.86 & 0.066 & 0.968 \\
\hline $3-1$ & 8.60 & 0.084 & 0.974 \\
\hline $3-2$ & 8.05 & 0.079 & 0.976 \\
\hline $3-3$ & 10.69 & 0.104 & 0.970 \\
\hline $3-4$ & 9.68 & 0.095 & 0.978 \\
\hline
\end{tabular}


to the settling rate of the gelatine mixture. There was a slight loss of TLD powder during recovery of approximately $3 \%$. Total recovery of the TLD powder was expected but a small loss of TLD powder during recovery from the gelatine mixture was found. A loss of $3 \%$ of the TLD powder resulted in an average recovery rate of $97 \%$ of the TLD powder. Although the loss was small it should be reduced furthex. The loss can occur from several portions of the procedure. Some of the TLD powder could settle to the bottom or sides of the form and adhere to the lining and become lost when the tissue substitute is removed from the lining. TLD powder could also be lost by not thoroughly rinsing the beaker in which in the mixture was dissolved, the filtering cup, and the filter gaskets. Additional losses could arise from the process of removing the powder from the filter by brushing.

Two TLD powder samples of $0.6 \mathrm{~g}$, one tenth of the gelatine mixture weight used, were measured. The samples were annealed for one hour at $400^{\circ} \mathrm{C}$ in a NEY M-525 series heater. Sample one was mixed with the gelatine and recovered from the mixture via the process previously outlined. A gelatine mixture of 60 grams was prepared and mixed with sample one and cast in a cylindrical shape. After recovery, the recovered TLD powder was weighed and recorded to account for the amount of TLD powder lost during recovery.

The data from the two samples of TLD powder that were exposed to the $35 \mathrm{mCi}{ }^{60} \mathrm{Co}$ gamma-ray source is shown in Table 8 . 
The control sample registered a slightly higher counting rate than the sample put through the gelatine process. A difference of $6.7 \%$ was noted between the samples. This can be accounted for from the small loss of TLD powder during recovery of the TLD powder from the gelatine mixture. If a trend of declining counts occur:red as the number of sections increased it would be assumed a small amount of gelatine remained attached to the processed TLD powder and was being vaporized, coating the optical lens of the reader. This would reduce the counting efficiency of the reader and produce continually declining count rates. This was not the case since the counting rate was approximately equal from beginning to end. Therefore the preparation and recovery procedure had no adverse effect on the TLD powder or reader.

The data obtained from the two irradiated gelatine-based forms are presented in Table 9. The total light output recorded in UC per segment is reported for the dissected form. The total light output recorded in UC obtained for the unsectioned model is reported for comparison only. The data from the portions of the sectioned model remained fairly constant demonstrating no degradation of the optical lens of the reader due to vaporized gelatine coating. The continued use of the reader without cleaning the optical lens confirmed the removal of all the gelatine from the TLD powder.

There was $72.3 \%$ difference between the sectioned and the whole molds. This could be attributed to powder losses during sectioning and recovery. Also TLD powder may have been 
Table 8. Total light output from individual sections as measure in uC

\begin{tabular}{|c|c|c|}
\hline Count Number & Control Sample & Processed Sample \\
\hline 1 & 32441 & 45130 \\
\hline 2 & 38162 & 25639 \\
\hline 3 & 24138 & 24756 \\
\hline 4 & 22545 & 22680 \\
\hline 5 & 24159 & 21030 \\
\hline 6 & 28574 & 19717 \\
\hline 7 & 22951 & 23437 \\
\hline 8 & 22767 & 23520 \\
\hline 9 & 19232 & 21603 \\
\hline 10 & 19226 & 25210 \\
\hline 11 & 24693 & 19546 \\
\hline 12 & 24140 & 22375 \\
\hline 13 & 25990 & 21642 \\
\hline 14 & 23982 & 18204 \\
\hline 15 & 21751 & 22622 \\
\hline 16 & 19434 & 26621 \\
\hline & & \\
\hline & & \\
\hline
\end{tabular}


distributed differently from one mold to another since they were mixed separately. If this was the cause of the difference a possible solution would be to mix the gelatine and the TLD powder, then distribute it to both molds. In this manner, both would have the same content and distribution of TLD powder. The difference between the sectioned and the unsectioned volume was less than a $3 \%$ difference which was the amount lost during recovery of the TLD powder. Therefore, it was assumed that the difference arose from losses of TLD powder during the recovery process. 
Table 9. Total light output recorded from the exposed gelatine mixture.

\begin{tabular}{|c|c|l||}
\hline Section & $\begin{array}{c}\text { Sectioned Gelatine } \\
\text { Mixture }\end{array}$ & $\begin{array}{c}\text { Unsectioned Gelatine } \\
\text { Mixture }\end{array}$ \\
\hline $1-1$ & 40479 & \\
\hline $1-2$ & 52746 & \\
\hline $1-3$ & 57739 & \\
\hline $1-4$ & 60719 & \\
\hline $2-1$ & 47453 & \\
\hline $2-2$ & 51152 & \\
\hline $2-3$ & 39253 & \\
\hline $2-4$ & 32506 & \\
\hline $3-1$ & 51519 & \\
\hline $3-2$ & 48453 & \\
\hline $3-3$ & 63786 & \\
\hline $3-4$ & 58266 & \\
\hline Total & 604071 & \\
\hline
\end{tabular}




\section{CHAPTER VI}

\section{CONCLUSIONS}

The objectives of this study were to identify a tirsue substitute for use as a volumetric dosimeter media, provide a procedure to prepare the volumetric dosimeter using the selected tissue substitute, and determine if the method for sectioning the tissue substitute and recovering the TLD powder were viable. These objectives were met providing a suitable tissue substitute and a method of experimentaily measuring the dose profiles from external radionuclides.

Currently improved geometries for use in Monte carlo codes are being written and improved methods to verify the new geometries are needed. This research is important in verifying the dose profiles obtained from Monte carlo code calculations. It may also be of interest to experimenters who wish to obtain dose profiles through existing volumetric phantoms.

The tissue substitute gelatine is one that has not received much attention. Gelatine matches the tissue properties of Reference Man at both low and high energies. The elemental composition and the electron density of the selected tissue substitute agreed well with that of Reference Man. In addition, the electron stopping powers and the mass attenuation coefficients provide a far hetter match than the other tissue substitutes considered in this comparison.

The procedure developed provides a method to produce a 
volumetric dosimeter which can be used to measure dose profiles. It also provides a method to evenly distribute TLD powder in the substitute which can be formed into most any shape. The recovery of TLD powder was accomplished with less that $3 \%$ loss of the powder. There was no retention of the tissue substitute with the TLD powder after recovery which if retained could adversely affect the TLD reader. The procedure provides a viable method to produce a volumetric dosimeter for use in dose profile measurements.

The methods developed have proven to work well through the experiments performed. They return a very high rate of the initial TLD powder used and if the powder reading systems are calibrated correctly promise to be the best system for experimentally measuring the dose profile for comparison to Monte Carlo codes. 


\section{References}

Aissi, A. Tsakeres, F.S. Poston, J.W. A molding technique for use in internal dosimetry studies. Health Phys. 42 (5) $713-716,1982$.

Aissi, A. Poston, J.W. An improved volumetric dosimeter for internal dose verification. Health Phys. 46 (2) 371-376, 1987 .

Attix, F. H. Introduction To Radiological Physics and Radiation Dosimetry. John Wiley and Sons, Inc 1986.

Chen, W.I. Poston, J.W. An evaluation of the distribution of absorbed dose in pediatric phantoms exposed to diagnostic medical $x$ rays. ORNL 5171, p.83, Oak Ridge National Laboratory, Oak Ridge, TN, October 1976.

Garry, S.M. Stansbury, P.S. Poston, J.W. Measurement of absorbed fractions for photon sources distributed uniformly in various organs of a heterogenous phantom. Health Phys. $28591-597,1975$.

Golikov, V.Y. Nikitin, V.V. Estimation of the Mean Organ Doses and the Effective Dose Equivalent From Rando Phantom Measurements. Health Phys. 56, 111-115, 1989.

Hall, D. A. The Chemistry of Connective Tissue. Charles C.Thomas Publishing Co., 1961.

Henson, G. C. The Texas A\&M TLD Counting Station User's Manual. Department on Nuclear Engineering, Texas A\&M University, December, 1987.

Hermann, K.P. Geworski, L. Muth, M. Harder, D. Polyethylene-based water-equivalent phantom material for $x$-ray dosimetry at tube voltages from 10 to $100 \mathrm{kV}$. Phys. Med. Biol. 30, 11951200,1985 .

Hermann, K.P. Geworski, L. Hatzky, T. Lietz, R. Harder, D. Muscle- and fat-equivalent polyethylene-based phantom materials for x-ray dosimetry at tube voltages below $100 \mathrm{kV}$. Phys. Med. Biol. 31, 1041-1046, 1986.

ICRP (1975). International Commission on Radiation protection, Report of the Task Group on Reference Man, ICRP Report 23, pergamon press, nxford.

ICRU (1984b). International Commission on Radiation Units and Measurements, Stopping powers for Electrons and Positrons, ICRU Report 37, Intcrnational Comisision on Raüiation units and Measurements, Bethesda, Maryland. 
ICRU (1989). International Commission on Radiation Units and Measurements, Tissue Substitutes in Radiation Dosimetry and Measurement, ICRU Report 44, International Commission on Radiation' itts and Measurements, Bethesda, Maryland.

Kienbock, R. Archives of the Roentgen Ray. 11, $17,1906$.

Mei, N.H. Warner, G.G. Stansbury, P.S. Poston, J.W. Effect of source organ size on absorbed fraction distribution. ORNL 5046 , p. 234-238, Oak Ridge National Laboratory, Oak Ridge, TN, September 1975.

Morrison, R. T. Boyd, R. N. Organic Chemistry Fourth Edition. New York University, 1983.

Rossi, H. H. Failla, G. Tissue-Equivalent Ionization Chambers. Nucleonics, 14, 32-37, 1956.

Shleien, B Terpilak, M. S. The Health Physics and Radiological Health Handbook. Nucleon Lecture Associates, Inc. 1987.

Stacey, A.J. Brevan, A.R. Dickens, C.W. A new phantom material employing depolymerised natural rubber. Br.J. Radiol. 34 510-515, August 1961.

Stansbury, P.S. Poston, J.W. In-phantom dosimetry of medical X rays. ORNL 5171, p. 81-82, Oak Ridge National Laboratory, oak Ridge, TN, October 1976.

Stenstrom, w. Acta Radiology, 7, 547, 1926.

Turner, J.E. Atoms, Radiation, and Radiation Protection. Pergamon Press, 1986.

Veis, A. The Macromolecular Chemistry of Gelatine. Academic Press, 1964 .

Veltidi, M. (1992) Kind \& Knox Inc. Private communication

Ward, A.G. Courts, A. The Science and Technology of Gelatine. Academic Press, 1977.

White, D.R. Martin, R.J. Darlison, R. Epoxy resin based tissue substitutes. Br.J. Radiol 50, 814-821, November 1977.

White, D.R. Tissue substitutes in oxperimental radiation mhysics. Med. Phys. 5, 464-479, 1973.

White, D.R. Constontinou, C. Martin, R.J. Foamed epoxy resinbased lung substitutes. Br.J. Radiol 59, 787-790, August 1386 . 
Wittmann, A. Morhart, A. Burger, G. Organ doses and effective dose equivalent. Radiation Protection Dosimetry. 12 (2) 101$106,1985$. 


\section{APPENDIX A}

DIM Atten(5, 21), U(21)

'Electron Stopping Power Data:

DATA .01, .015,.02,.03,.04,.05,.06,.08,.1,.15,.2,.3, $4, .5, .6, .8,1,1.5,2,3,4$

DATA 20.14, 14.71,

$11.77,8.63,6.95,5.90,5.18,4.25,3.677,2.89,2.49,2.09,1.90,1.79,1.7$ $3,1.66,1.63,1.61,1.62,1.66,1.70$

DATA

$51.25,36.82,29.17,21.10,16.87,14.24,12.45,10.15,8.74,6.82,5.85,4$. $90,4.45,4.20,4.05,3.89,3.82,3.80,3.84,3.94,4.05$

DATA

$19.37,14.19,11.38,8.36,6.75,5.74,5.04,4.15,3.59,2.83,2.45,2.07,1$. $89,1.79,1.73,1.68,1.65,1.67,1.70,1.77,1.84$

DATA

$19.96,14.59,11.68,8.57,6.91,5.87,5.15,4.23,3.66,2.89,2.50,2.10,1$. $92,1.82,1.76,1.70,1.68,1.69,1.72,1.79,1.86$

'Reading data into the matrix:

FOR $I=1$ TO 5

FOR $\mathrm{J}=1 \mathrm{TO} 21$

NEXT J

READ Atten (I, J)

NEXT I

'Obtaining the emperical data:

21 INPUT "Name of Composition"; Names

INPUT "How many carbon atoms", C

INPUT "How many hydrogen atoms", H

INPUT "How many oxygen atoms", o

INPUT "How many nitrogen atoms", N

PRINT "Is this data correct? ( $Y / N)$ "

PRINT "carbon"; C, "hydrogen"; $\mathrm{H}$

PRINT "oxygen"; O, "nitrogen";

INPUT Answers

IF Answer $\$=$ "N" OR Answer $\$=" n$ " THEN GOTO 21

'Calculating the total mass attenuation crosssection:

Ftot $=\mathrm{C}+\mathrm{H}+\mathrm{O}+\mathrm{N}$

LPRINT Names

LPRINT "C"; $\mathrm{C}$; " $\mathrm{H} "$; $\mathrm{H} ; " \mathrm{O} " ; \mathrm{O} ; " \mathrm{~N}$ "; $\mathrm{N}$

LPRINT" ":

LPRINT "MeV"

FOR $\mathrm{K}=1$ TO 21

$U(K)=\operatorname{Atten}(2, K) *(C / E$ tot $) \neq \operatorname{Atten}(3, K) *(H / F t o t)+$ 
$\operatorname{Atten}(4, K) *(0 /$ Ftot $)+\operatorname{Atten}(5, K) *(N /$ Ftot $)$

PRINT Atten $(1, K) ; U(K)$

LPRINT Atten $(1, K) ; U(K)$

NEXT K

INPUT "Do you want to calculate another $\operatorname{set}(\mathrm{Y} / \mathrm{N})$ ?", Answer

IF Answer $\$=" Y "$ OR Answer\$ = "Y" THEN GOTO 21

LPRINT CHR\$(12)

END 


\section{APPENDIX B}

DIM Atten(5, 21), U(21)

'Mass Attenuation Crosssection Data:

DATA .01, .015,.02,.03,.04,.05,.06,.08,.1,.15,.2,.3, $.4, .5, .6, .8,1,1.5,2,3,4$

DATA $2.23, .797, .434, .253, .205, .185, .174, .162, .152, .135$, $.123, .107, .0953, .087, .0805, .0707, .0637, .0519, .0433$, $.0356, .0305$

DATA .385,.3\%6,.369,.357,.346,.335,.326,.309,.294,.265, $.243, .211, .189, .173, .16, .14, .126, .103, .0875, .0691, .0581$

DATA $5.82,1.75, .83, .373, .257, .211, .19, .168, .156, .137$,

$.124, .107, .0957, .0871, .0805, .0707, .0637, .0518, .0445$, $.0359, .031$

DATA $3.77,1.19, .602, .304, .229, .196, .181, .164, .154, .136$, $.124, .107, .0953, .087, .0805, .0707, .0636, .0518, .0444$; $.0357, .0308$

'Reading data into the matrix:

FOR I $=1$ TO 5

FOR $\mathrm{J}=1$ TO 21

READ Atten ( $I, J)$

NEXT I NEXT J

'Obtaining the emperical data:

21 INPUT "Name of Composition"; Name\$

INPUT "How many carbon atoms", C

INPUT "How many hydrogen atoms", H

INPUT "How many oxygen atoms", O

INPUT "How many nitrogen atoms", N

PRINT "Is this data correct? ( $\mathrm{Y} / \mathrm{N}$ )"

PRINT "carbon"; C, "hydrogen"; $\mathrm{H}$

PRINT "oxygen"; O, "nitrogen"; N

INPUT Answer $\$$

IF Answer\$ = "N" OR Answer\$ = "n" THEN GOTO 21

'Calculating the total mass attenuation crosssection:

Ftot $=\mathrm{C}+\mathrm{H}+\mathrm{O}+\mathrm{N}$

LPRINT Name\$

LPRINT "C"； $\mathrm{C}$; " $\mathrm{H} "$; $\mathrm{H}$; " O"; O; " $\mathrm{N} "$; N

LPRINT " ":

LPRINT "MeV"

FOR $\mathrm{K}=1$ TO 2.1

$\mathrm{U}(\mathrm{K})=\operatorname{Atten}(2, \mathrm{~K}) *(\mathrm{C} / \mathrm{Ftot})+\operatorname{Atten}(3, \mathrm{~K}) *(\mathrm{H} / \mathrm{Ftot})+$

$\operatorname{Atten}(4, K) *(0 /$ Ftot $)+\operatorname{Atten}(5, K) \star(N /$ Ftot $)$ 
PRINT Atten $(1, K) ; U(K)$

LPRINT Atten $(1, K) ; U(K)$

NEXT $K$

INPUT "Do you want to calculate another set(Y/N)?", Answer\$ IF Answer $\$=$ "Y" OR Answer $\$=$ "Y" THEN GOTO 2.1 LPRINT CHR\$(12)

END 
APPENDIX C

Reference Man

\begin{tabular}{|c|c|c|}
\hline $\begin{array}{c}\text { Energy } \\
(\mathrm{MeV})\end{array}$ & $\begin{array}{c}\text { Electron Stopping } \\
\text { Power } \\
\left(\mathrm{MeV} \mathrm{cm}^{\wedge} 2 / \mathrm{g}\right)\end{array}$ & $\begin{array}{c}\text { Mass Attenuation } \\
\text { Coefficient } \\
\left(\mathrm{g} / \mathrm{cm}^{\wedge} 2\right)\end{array}$ \\
\hline 0.01 & 39.56 & 1.93 \\
\hline 0.015 & 28.52 & 0.76 \\
\hline 0.01 & 22.64 & 0.49 \\
\hline 0.03 & 16.43 & 0.35 \\
\hline 0.04 & 13.13 & 0.51 \\
\hline 0.05 & 11.11 & 0.29 \\
\hline 0.06 & 9.73 & 0.27 \\
\hline 0.08 & 7.94 & 0.26 \\
\hline 0.1 & 6.85 & 0.24 \\
\hline 0.15 & 5.35 & 0.22 \\
\hline 0.2 & 4.60 & 0.20 \\
\hline 0.3 & 3.86 & 0.17 \\
\hline 0.4 & 3.51 & 0.15 \\
\hline 0.5 & 3.31 & 0.14 \\
\hline 0.6 & 3.19 & 0.13 \\
\hline 0.8 & 3.07 & 0.11 \\
\hline 1 & 3.02 & 0.10 \\
\hline 1.5 & 3.01 & 0.08 \\
\hline 2 & 3.04 & 0.07 \\
\hline 3 & 3.12 & 0.06 \\
\hline 4 & 3.21 & 0.05 \\
\hline
\end{tabular}


Gelatine

\begin{tabular}{|c|c|c|}
\hline $\begin{array}{c}\text { Energy } \\
(\mathrm{MeV})\end{array}$ & $\begin{array}{c}\text { Electron Stopping } \\
\text { Power } \\
(\mathrm{MeV} \mathrm{Cm} \wedge 2 / \mathrm{g})\end{array}$ & $\begin{array}{c}\text { Mass Attenuation } \\
\text { Coefficient } \\
\left(\mathrm{g} / \mathrm{cm}^{\wedge} 2\right)\end{array}$ \\
\hline 0.01 & 38.56 & 2.14 \\
\hline 0.015 & 27.83 & 0.81 \\
\hline 0.01 & 22.10 & 0.51 \\
\hline 0.03 & 16.04 & 0.35 \\
\hline 0.04 & 12.85 & 0.30 \\
\hline 0.05 & 10.86 & 0.28 \\
\hline 0.06 & 9.50 & 0.27 \\
\hline 0.08 & 7.76 & 0.25 \\
\hline 0.1 & 6.69 & 0.24 \\
\hline 0.15 & 5.23 & 0.22 \\
\hline 0.2 & 4.50 & 0.20 \\
\hline 0.3 & 3.77 & 0.17 \\
\hline 0.4 & 3.43 & 0.15 \\
\hline 0.5 & 3.24 & 0.14 \\
\hline 0.6 & 3.12 & 0.13 \\
\hline 0.3 & 3.00 & 0.11 \\
\hline 1 & 2.95 & 0.10 \\
\hline 1.5 & 2.94 & 0.08 \\
\hline 2 & 2.98 & 0.07 \\
\hline 3 & 3.06 & 0.06 \\
\hline 4 & 3.15 & 0.05 \\
\hline
\end{tabular}


Pate

\begin{tabular}{|c|c|c|}
\hline $\begin{array}{c}\text { Energy } \\
(\mathrm{MeV})\end{array}$ & $\begin{array}{c}\text { Electron Stopping } \\
\text { Power } \\
\left(\mathrm{MeV} \mathrm{cm}^{\wedge} 2 / \mathrm{g}\right)\end{array}$ & $\begin{array}{c}\text { Mass Attenuation } \\
\text { Coefficient } \\
\left(g / \mathrm{cm}^{\wedge} 2\right)\end{array}$ \\
\hline 0.01 & 40.88 & 1.00 \\
\hline 0.015 & 29.45 & 0.52 \\
\hline 0.01 & 23.37 & 0.39 \\
\hline 0.03 & 16.94 & 0.32 \\
\hline 0.04 & 13.56 & 0.30 \\
\hline 0.05 & 11.46 & 0.29 \\
\hline 0.06 & 1.0 .02 & 0.28 \\
\hline 0.08 & 8.18 & 0.26 \\
\hline 0.1 & 7.05 & 0.25 \\
\hline 0.15 & 5.51 & 0.22 \\
\hline 0.2 & 4.73 & 0.20 \\
\hline 0.3 & 3.96 & 0.18 \\
\hline 0.4 & 3.60 & 0.16 \\
\hline 0.5 & 3.39 & 0.14 \\
\hline 0.6 & 3.28 & 0.13 \\
\hline 0.8 & 3.14 & 0.12 \\
\hline 1 & 3.09 & 0.11 \\
\hline 1.5 & 3.07 & 0.09 \\
\hline 2 & 3.10 & 0.07 \\
\hline 3 & 3.18 & 0.06 \\
\hline 4 & 3.27 & 0.05 \\
\hline
\end{tabular}


$A-150$

\begin{tabular}{|c|c|c|}
\hline $\begin{array}{c}\text { Energy } \\
(\mathrm{MeV})\end{array}$ & $\begin{array}{c}\text { Electron Stopping } \\
\text { Power } \\
(\mathrm{MeV} \mathrm{cm`2/g)}\end{array}$ & $\begin{array}{c}\text { Mass Attenuation } \\
\text { coefficient } \\
\left(\mathrm{g} / \mathrm{cm}^{\wedge} 2\right)\end{array}$ \\
\hline 0.01 & 38.48 & 1.22 \\
\hline 0.015 & 27.74 & 0.57 \\
\hline 0.01 & 22.03 & 0.41 \\
\hline 0.03 & 15.98 & 0.32 \\
\hline 0.04 & 12.80 & 0.29 \\
\hline 0.05 & 10.82 & 0.27 \\
\hline 0.06 & 9.47 & 0.26 \\
\hline 0.08 & 7.73 & 0.25 \\
\hline 0.1 & 6.66 & 0.24 \\
\hline 0.15 & 5.21 & 0.21 \\
\hline 0.2 & 4.47 & 0.19 \\
\hline 0.3 & 3.75 & 0.17 \\
\hline 0.4 & 3.40 & 0.15 \\
\hline 0.5 & 3.21 & 0.14 \\
\hline 0.6 & 3.10 & 0.13 \\
\hline 0.8 & 2.98 & 0.11 \\
\hline 1 & 2.92 & 0.10 \\
\hline 1.5 & 2.90 & 0.08 \\
\hline 2 & 2.93 & 0.07 \\
\hline 3 & 3.01 & 0.06 \\
\hline 4 & 3.09 & 0.05 \\
\hline
\end{tabular}



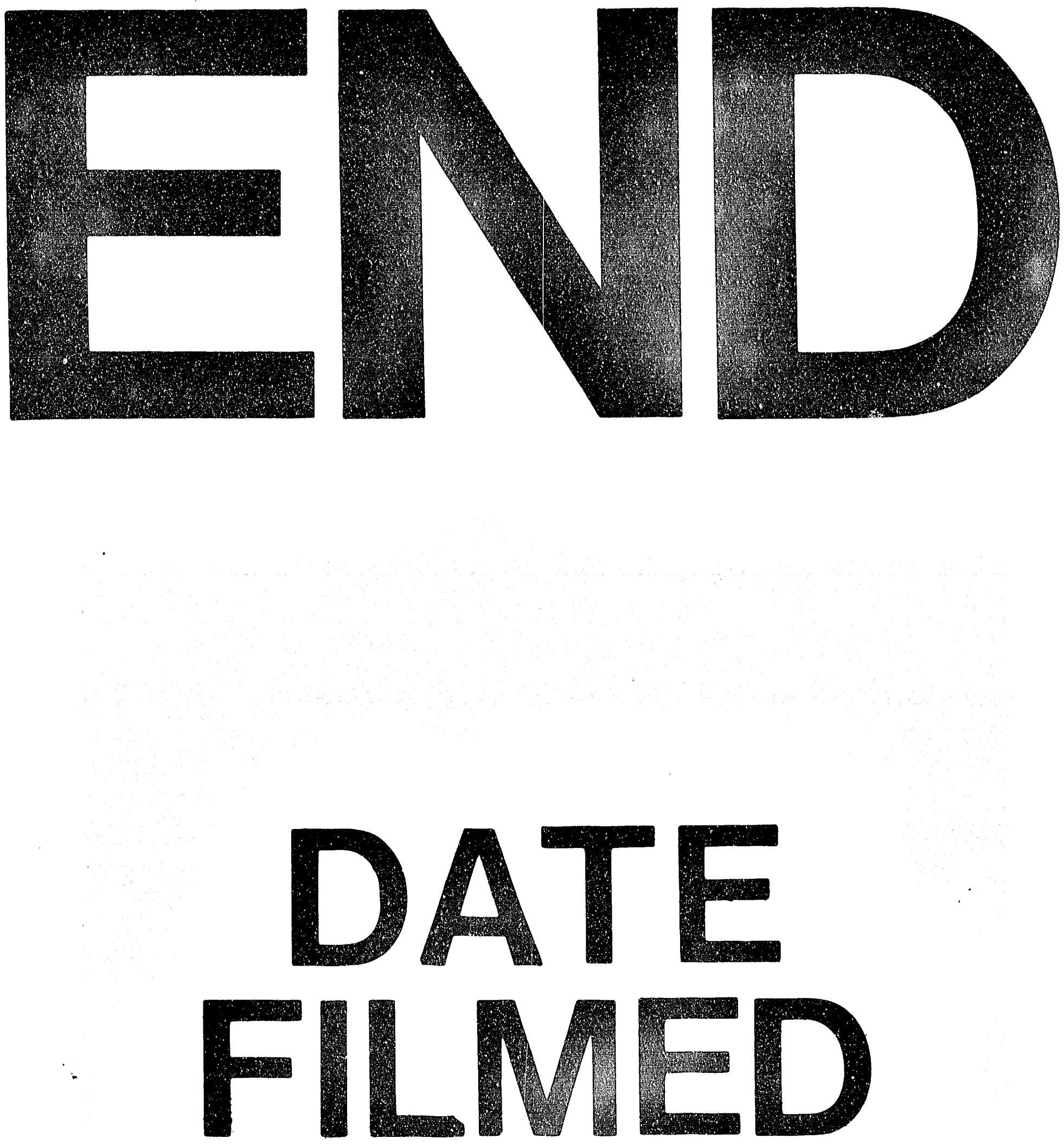

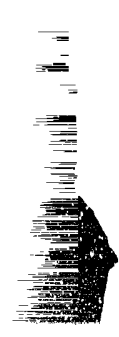
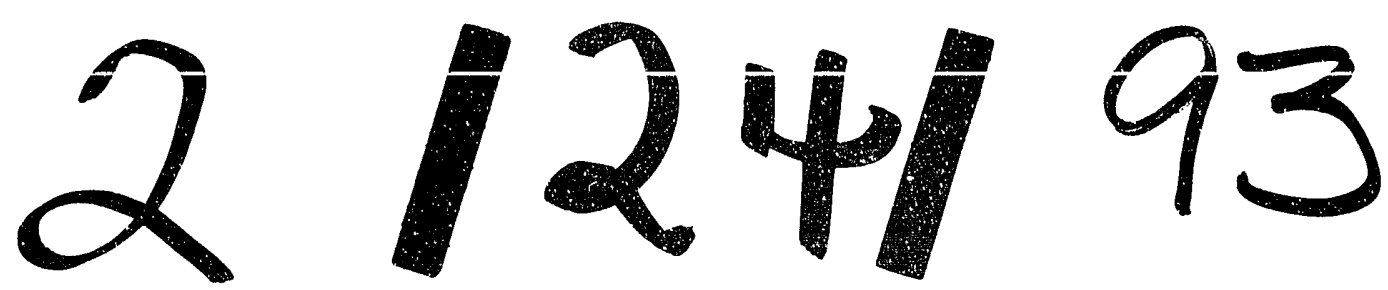
